\title{
Self-Enhancement of Scalar and Vector Holographic Gratings in Azobenzene Molecular Glassy Films
}

\author{
Andris Ozols ${ }^{*}$, Valdis Kokars' ${ }^{1}$ Peteris Augustovs' ${ }^{1}$ Dmitrijs Malinovskis ${ }^{2}$, \\ Kaspars Traskovskis ${ }^{1}$, Elmars Zarins ${ }^{1}$, Girts Ivanovs ${ }^{2}$ \\ ${ }^{1}$ Faculty of Material Science and Applied Chemistry, Riga Technical University, Riga, Latvia \\ ${ }^{2}$ Faculty of Electronics and Telecommunications, Riga Technical University, Riga, Latvia \\ Email: aozols@latnet.Iv
}

Received 11 February 2014; revised 9 March 2014; accepted 1 April 2014

Copyright (C) 2014 by authors and Scientific Research Publishing Inc.

This work is licensed under the Creative Commons Attribution International License (CC BY). http://creativecommons.org/licenses/by/4.0/

\section{(c) (i) Open Access}

\begin{abstract}
Self-enhancement (SE) effect of scalar and vector holographic gratings (HG) recorded in three different azobenzene molecular glassy films is experimentally studied in both transmission and reflection modes at 532 and $633 \mathrm{~nm}$. The maximal SE factor (the ratio of diffraction efficiency to its initial value) SEF = 42 has been achieved. It is shown that the model of complementary HG can be applied also in scalar transmission thin HG case to explain coherent SE. The possibility of vector HG coherent $S E$ in transmission mode is experimentally demonstrated for the first time (SEF = 4.3). The possibility of coherent HG SE in reflection mode is also established for the first time (SEF = 21). HG recording processes as well as coherent SE processes are found to be independent in transmission and reflection modes being determined by volume and surface relief $H G$, respectively. The permittivity gradient mechanism is proposed to explain the coherent SE of surface relief HG. Both HG recording and coherent SE efficiencies strongly decrease when HG period is decreased from 2 $\mu \mathrm{m}$ to $0.5 \mu \mathrm{m}$. No relaxational SE effect is found. Coherent SE effect in molecular glasses is found to be weaker than in inorganic materials.
\end{abstract}

\section{Keywords}

Self-Enhancement of Holograms, Light Polarization, Holographic Gratings, Azobenzene Molecular Glasses

\footnotetext{
${ }^{*}$ Corresponding author.
}

How to cite this paper: Ozols, A., Kokars, V., Augustovs, P., Malinovskis, D., Traskovskis, K., Zarins, E. and Ivanovs, G. (2014) Self-Enhancement of Scalar and Vector Holographic Gratings in Azobenzene Molecular Glassy Films. Optics and Photonics Journal, 4, 143-152. http://dx.doi.org/10.4236/opj.2014.46015 


\section{Introduction}

Organic materials, especially azobenzene compounds, are of a wide interest for applications in holography and nonlinear optics because they enable much easier tailoring of their properties than inorganic ones [1]. In this paper, we have studied self-enhancement (SE) possibilities of vector and scalar holographic gratings (HG) in azobenzene molecular glassy films produced in the Faculty of Material Science and Applied Chemistry, Riga Technical University.

SE of a nonstationary hologram is the increase in its diffraction efficiency (DE) over time under the stimulus of a single beam light irradiation or simply in the dark [2] [3]. The SE effect was reported for the first time in 1973 by Gaylord et al. [4] for phase holograms in photorefractive $\mathrm{LiNbO}_{3}$ :Fe crystals. It has been observed also in photochromic $\mathrm{KBr}$ crystals [5], sillenite-type photorefractive $\mathrm{Bi}_{12} \mathrm{Ti}_{0.76} \mathrm{~V}_{0.24} \mathrm{O}_{20}$ crystals [6], amorphous chalcogenide As-S, As-Se films [2] [3] [7], dichromated gelatin and polyvinyl alcohol films [8] and photopolymers [9]. Three types of SE can be distinguished: i) coherent SE due to the holographic recording by diffracted waves; ii) incoherent SE due to the contrast and/or transmission increase of a hologram by incoherent light; iii) relaxational (or dark) SE due to the contrast and/or transmission increase of a hologram by thermostimulated relaxation processes. All three SE types can take place simultaneously. SE can also be regarded as a two-stage hologram recording method, which is profitable when the recording energy or exposure time is limited at the first stage. Such a recording method also has advantage of a large vibration stability at the second stage. SE characterizes recording processes as well. It has been used by us to determine the transport characteristics and polar axis direction of $\mathrm{LiNbO}_{3}$ :Fe crystals, disorder correlation length in an amorphous semiconductors, etc. [2] [4] [10]. SE effect of holograms in azobenzene derivatives is rarely studied. Our previous studies [11] have shown that sometimes and weakly it takes place in azobenzene oligomers. This paper is devoted to the coherent and relaxational SE studies in our new molecular glassy films in comparison with previously synthesized azobenzene derivative films and with our results in inorganic materials. New SE possibilities have been experimentally investigated: 1) coherent SE of vector HG; 2) coherent SE of HG in reflection mode. It is found that not only coherent SE of usual scalar HG in transmission mode can take place but also the coherent SE of vector HG and the coherent SE of scalar HG in reflection mode can take place. These effects have been revealed for the first time, to our knowledge. Dark relaxation of HG in azobenzene glassy films is also studied.

\section{Samples and Experiments}

Studied azobenzene molecular glasses were synthesized and characterized by our group. They included 8a or 3-(4-(bis(2-(trityloxy)ethyl)amino)phenyl)-2-(4-(2-bromo-4-nitrophenyl) diazenyl)phenyl)acrylonitrile (Figure 1, studied also in [12]), W-50 or 2-(2-(-4-(-(4-(bis(2-(trityloxy)ethyl)amino)phenyl)diazenyl)styryl)-6-styryl-4H-

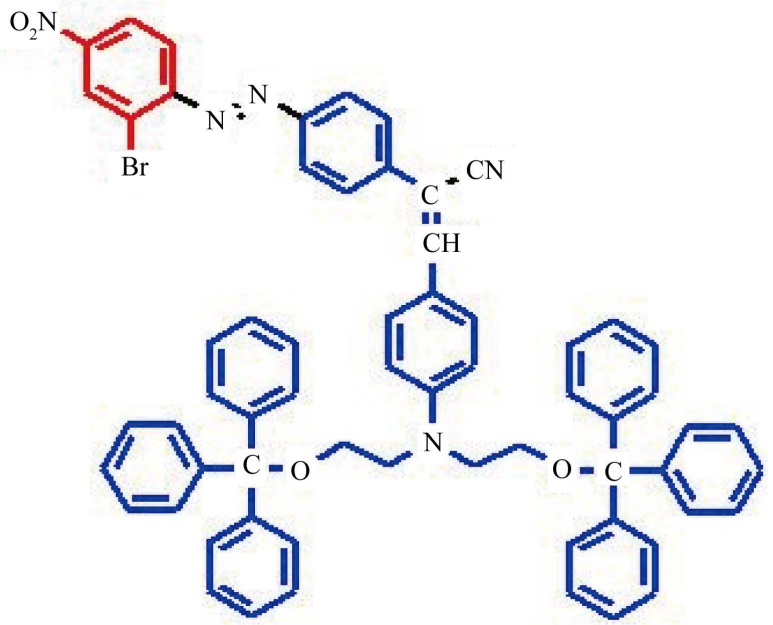

Figure 1. Chemical structure of $\mathbf{8 a}$ or (4(bis(2-(trityloxy)ethyl)amino) phenyl)-2-(4-(2-bromo-4nitrophenyl) diazenyl) phenyl)acrylonitrile molecule. It is stilbene azobenzene derivative. Long wavelength absorption maximum at $\lambda_{\max }=510 \mathrm{~nm}$ (in dichloromethane solvent). 
pyran-4-ylidene)-2H-indene-1,3-dione (Figure 2), and W-75 or 2-(3-(-4-(-(4-(bis(2-(trityloxy)ethyl)amino) phenyl)diazenyl)styryl)-5,5-dimethylcyclohex-2-enylidene)malo-nonitrile (Figure 3). The trans form (long wavelength) absorption maxima $\left(\lambda_{\max }\right)$ of these films were centered around 510, 478 and $504 \mathrm{~nm}$, respectively. Thin films of these glasses were spin-coated on glass substrates. Their thickness was in the $1.6-3 \mu \mathrm{m}$ range The size of the samples were about $7 \times 7 \mathrm{~cm}^{2}$. We took one sample of each azobenzene molecular glassy film.

Holographic gratings with the period of $2 \mu \mathrm{m}$ were recorded and read out either by KLASTECH DENICAFC 532 - 300 diode pumped solid state laser (recording and readout wavelengths $\lambda_{1}=\lambda_{2}=532 \mathrm{~nm}$ ) or by Melles Griot 25LH928-230 He-Ne gas laser $\left(\lambda_{1}=\lambda_{2}=632.8 \mathrm{~nm} \approx 633 \mathrm{~nm}\right)$ with two equally strong unfocused beams (Figure 4). To see the effect of the recording medium spatial resolution some experiments have been carried out also with the HG period of $0.5 \mu \mathrm{m}$. The lasers operated in CW mode. The $1 / \mathrm{e}^{2}$ beam diameters of these lasers were 1.47 and $1.80 \mathrm{~mm}$, respectively. The recording light intensity $(I)$ was $1.2-1.5 \mathrm{~W} / \mathrm{cm}^{2}$. Thus holographic gratings were recorded at the long wavelength side of the trans form absorption peaks. Linear $p-p$ (scalar recording) and $s-p$ (vector recording) recording beam light polarizations were used. First-order self-diffraction efficiency, SDE, was continuously measured as the function of exposure time $(t)$ by OPHIR Nova II or Laserstar power meter and stored in the PC memory.

SDE is a ratio of the first-order diffracted beam power to the power of the more distant recording beam when both recording beams are present. The mathematical relation between SDE and diffraction efficiency, DE (the ratio of the minus first-order beam power to the incident readout beam power) is described in [13]. In our experiments we have estimated that $\mathrm{SDE} \approx(0.5-1.6) \mathrm{DE}$. The readout of HG was simultaneously made both in transmission and reflection modes (Figure 4). We estimate that accuracy of determined SDE and DE values were about $2 \%$.

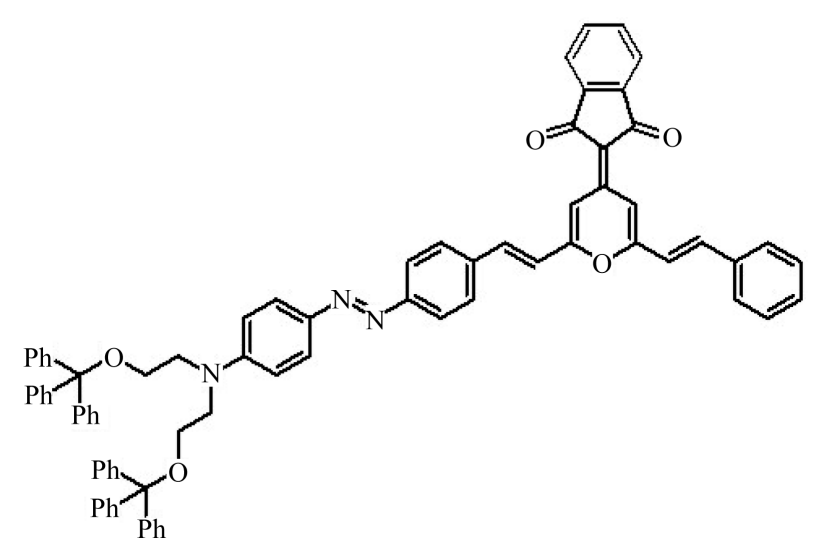

Figure 2. Chemical structure of a $\mathbf{W}-\mathbf{5 0}$ or 2-(2-(-4-(-(4-(bis(2(trityloxy)ethyl)amino)phenyl)diazenyl) styryl)-6-styryl-4H-pyran4-ylidene)-2H-indene-1,3-dione molecule. Long wavelength absorption maximum at $\lambda_{\max }=478 \mathrm{~nm}$ (in dichloromethane solvent).

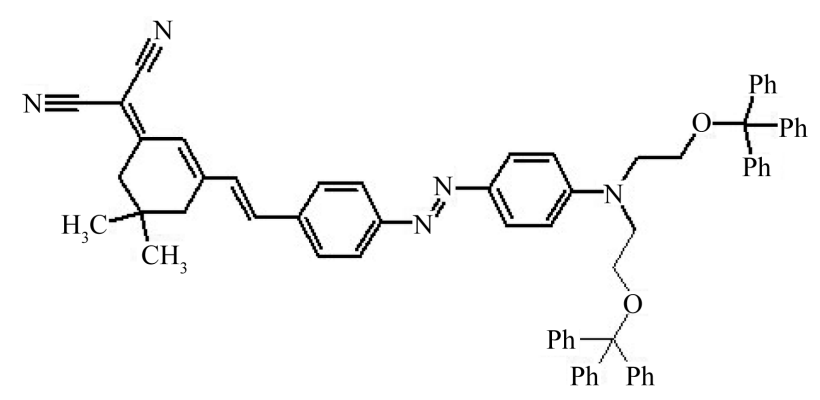

Figure 3. Chemical structure of a W-75 or 2-(3-(-4-(-(4-(bis(2-(trityloxy)ethyl)amino)phenyl)diazenyl) styryl)-5,5-dimethylcyclohex2-enylidene)malononitrile molecule. Long wavelength absorption maximum at $\lambda_{\max }=504 \mathrm{~nm}$ (in dichloromethane solvent). 


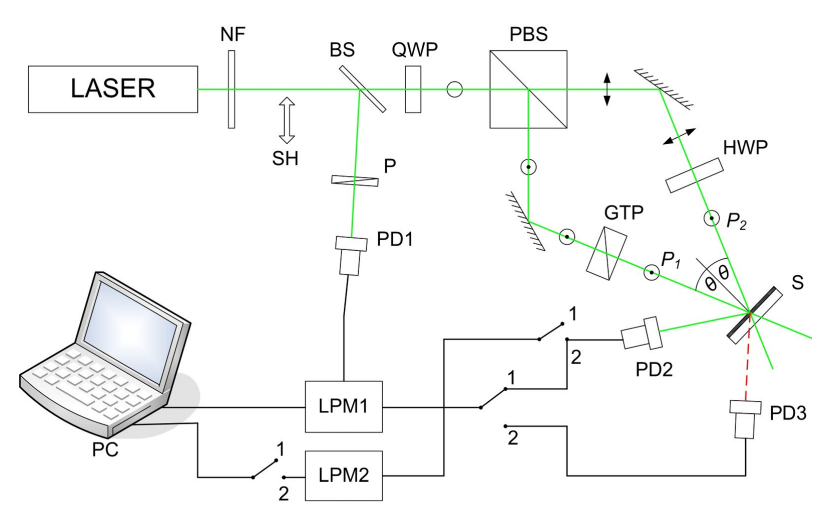

\begin{abstract}
Figure 4. Holographic setup for the recording with s-s polarizations. NF-neutral filters, SH-shutter, BS-beamsplitter, QWP-quarter-wave plate, HWP-half-wave plate, PBS-polarization beam splitter, GTP-Glan-Thompson prism, S-sample, P-polarizer, PD1 - photodetector serving for calibration of SDE and DE measurements, PD2photodetector for reflection SDE and DE measurements, PD3-photodetector for transmission SDE and DE measurements. LPM-laser power meter, PC-personal computer. Position 1-reflection SDE measurements, position 2-simultaneous reflection and transmission SDE measurements. In the case of other recording beam polarizations the corresponding half-wave plates or quarter-wave plates in the beams $P_{1}$ and $P_{2}$ before the sample were either inserted or removed. The setup is shown for SDE measurements. In the case of DE measurements before and during the coherent SE the $P_{2}$-beam was blocked and photodetector PD3 was slightly shifted to the position of the transmitted $P_{2}$ beam to measure the transmission first-order DE.
\end{abstract}

As mentioned, the main goal was to study the SE effect of gratings. To do this, HG were recorded up to the initial $\mathrm{DE} \approx 0.06 \%-0.1 \%$ and then were read out by one of the recording beams in the case of coherent SE experiments, or simply kept in the dark and then readout by a weak beam at the recording angle in the case of HG relaxation measurements. As we have shown in Section 3, the contribution of coherent SE in DE growth during the exposure by one of the recording beams is much higher than contributions of incoherent and relaxational SE. Therefore, we denote these experiments as coherent SE experiments. The readout beam was $p$-polarized in the case of scalar $(p-p)$ recording, and it was s-polarized in the case of vector $(s-p)$ recording.

Two quantities were used to characterize the SE effect which we have introduced in our previous papers [2] [3] [5] [10]. First, the ratio of $\mathrm{DE}$ to its initial value $\mathrm{DE}_{0}, \xi=\mathrm{DE} / \mathrm{DE}_{0}$, which we call the SE factor (SEF) or relative DE. Second, the SE efficiency, $\alpha=(\xi-1) / I_{1} t$ where $I_{1}$ is the readout beam intensity, $t$ - the exposure time. SE efficiency is measured in $\mathrm{cm}^{2} / \mathrm{J}$, and it characterizes the sensitivity of the material with respect to coherent SE process. All the measurements have been performed at room temperature.

\title{
3. Results and Discussion
}

The results of SE experimental studies are presented in Figures 5-14 and Table 1, Table 2.

The following observations are made. First, HG SE takes place in the studied azobenzene molecular glassy films but not in all cases (Figures 5-10 and Table 1). Second, coherent SE can be quite efficient even in the case of thin HG, contrary to the previous suggestions that coherent SE can be efficient only in thick hologram case [4] [10]. The highest SE factor of 42 has been achieved in sample 8a at $532 \mathrm{~nm}$ in transmission mode (Figure 5). The corresponding Klein's factor $Q=2 \pi \lambda d / n_{0} \Lambda^{2}$ (where $d$ is HG thickness, $n_{0}$ is the average refractive index of HG, $\Lambda$-its period) is 0.9 which clearly manifests that HG is thin [14].

Third, coherent SE of vector HG in transmission mode is possible. Fourth, coherent SE of HG in reflection mode is possible. Fifth, there is no strict correlation between coherent SE in the case of $p-p$ and $s-p$ gratings, as well as between coherent SE in transmission and reflection modes. Sixth, coherent SE in sample 8a dramatically decreases at small HG periods (Figure 7). Seventh, no relaxational SE is observed in sample 8a (Table 2).

Let us discuss these observations. In our previous papers [12] [13] we have come to the conclusion that HG recording in our organic molecular glasses at $532 \mathrm{~nm}$ is due to the azochromophore photo orientation in the process of trans-cis photoisomerization with a possible contribution of azochromophore photodegradation via 


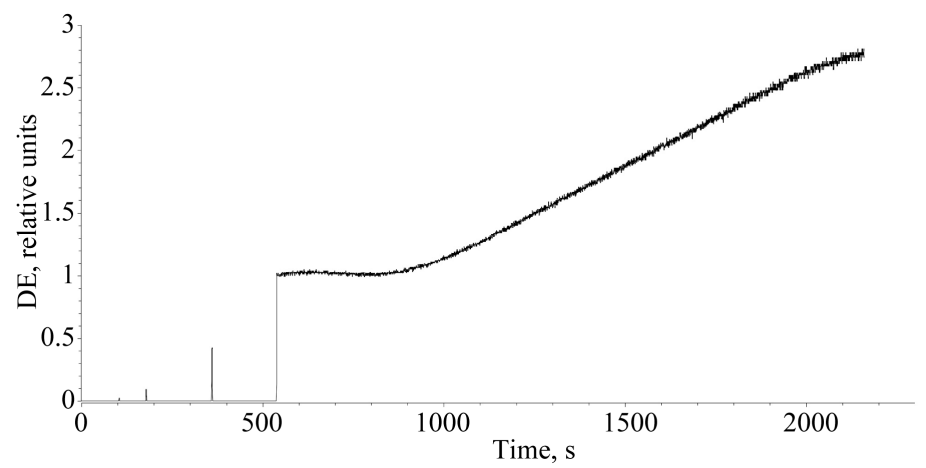

Figure 5. Coherent SE of $p$-p HG (i.e., HG recorded by two $p$-polarized beams) in sample 8a. Probing with $p$-beam. Transmission mode, $532 \mathrm{~nm}$, HG period is $2 \mu \mathrm{m}$. SE factor of 42 was achieved after 144 minutes of exposure (not shown). $\mathrm{DE}=1$ corresponds to the $\mathrm{DE}$ equal to the initial diffraction efficiency of HG recorded with two beams. The first two peaks correspond to the probing of DE in the process of initial HG recording.

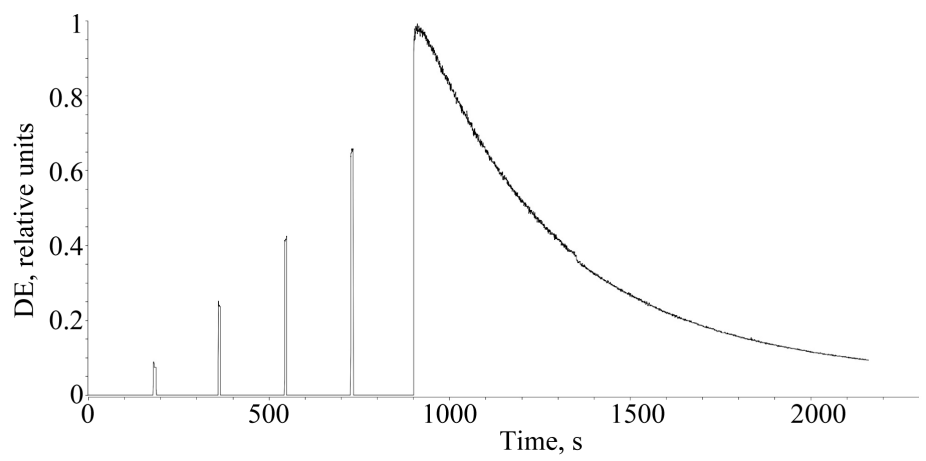

Figure 6. The lack of coherent SE of $s-p$ HG in sample 8a. Transmission mode, $532 \mathrm{~nm}$. HG period is $2 \mu \mathrm{m}$. Readout with the s-beam. The first four peaks correspond to the trial DE measurements until DE $=1$ is achieved.

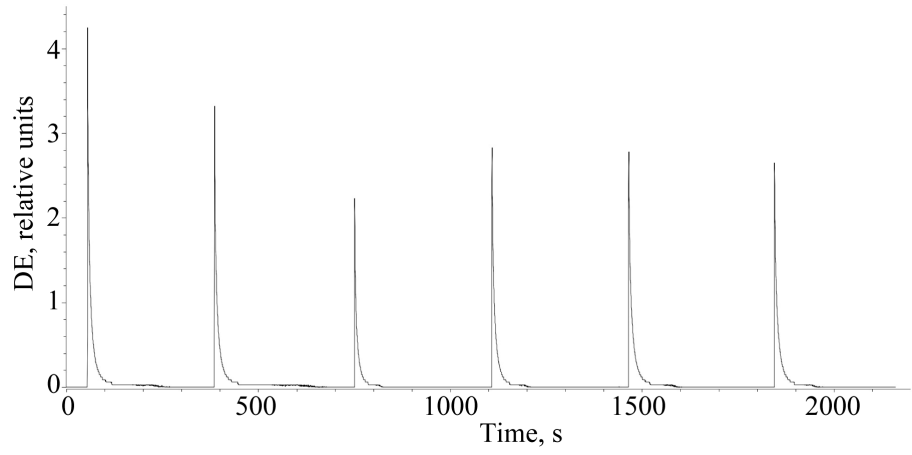

Figure 7. The lack of $p$ - $p$ HG SE in sample $8 \mathbf{a}$ at $633 \mathrm{~nm}$ and $0.5 \mu \mathrm{m}$ period. Transmission mode. The film is almost reversible because all peaks correspond to DE time dependences during recording and readout at the same film site.

polarization selective photoinduced N-N bond breaking. These processes are accompanied by mass transfer enabled by athermal fluidization [15]. As the result, photoinduced changes in refractive index and absorption coefficient, as well as in surface relief are produced. The resulting HG is mainly the phase one. 


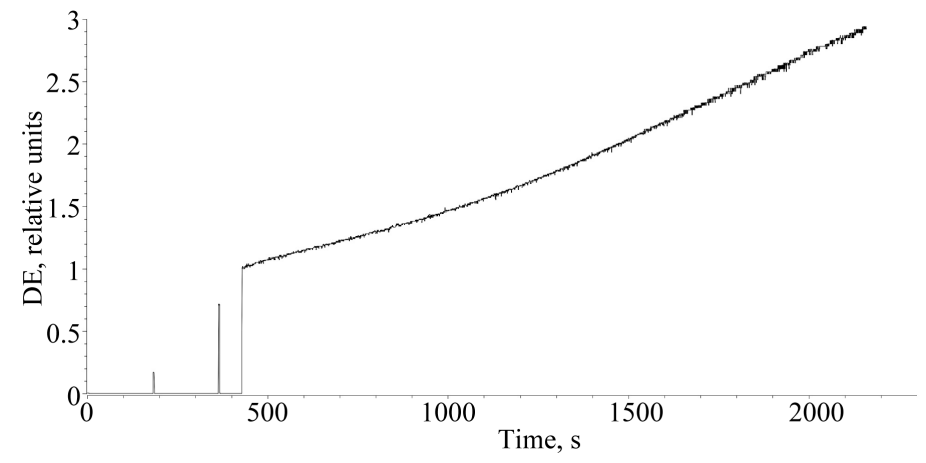

Figure 8. Coherent SE of $s-p$ HG in sample W-50. Probing with the $s$-beam. Transmission mode, $532 \mathrm{~nm}$, HG period is $2 \mu \mathrm{m}$. SE factor of 4.3 was achieved in 37 minutes (not shown). $\mathrm{DE}=1$ corresponds to the DE equal to the initial diffraction efficiency of HG recorded with two beams. The first two peaks correspond to the probing of DE in the process of initial HG recording.

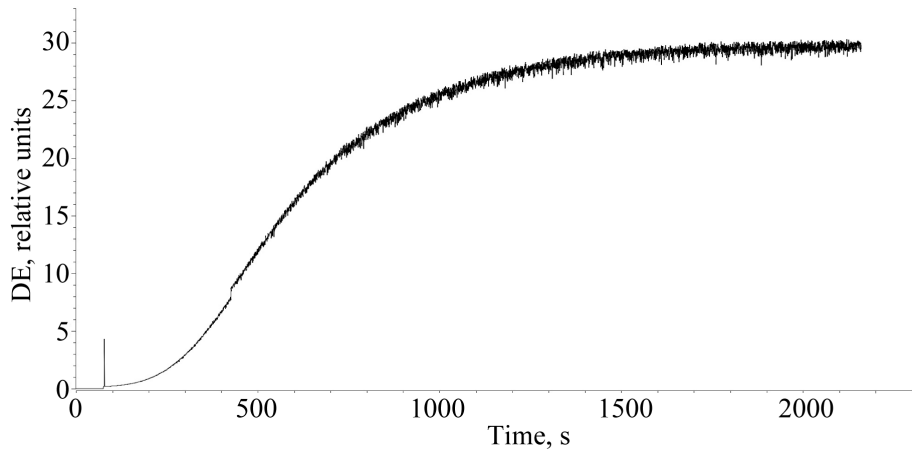

Figure 9. Coherent SE of $p$ - $p$ HG in sample $\mathbf{W}$-75. Transmission mode, $532 \mathrm{~nm}$, HG period is $2 \mu \mathrm{m}$. DE $=1$ corresponds to the DE equal to the initial diffraction efficiency of HG recorded with two beams (about $0.1 \%)$.

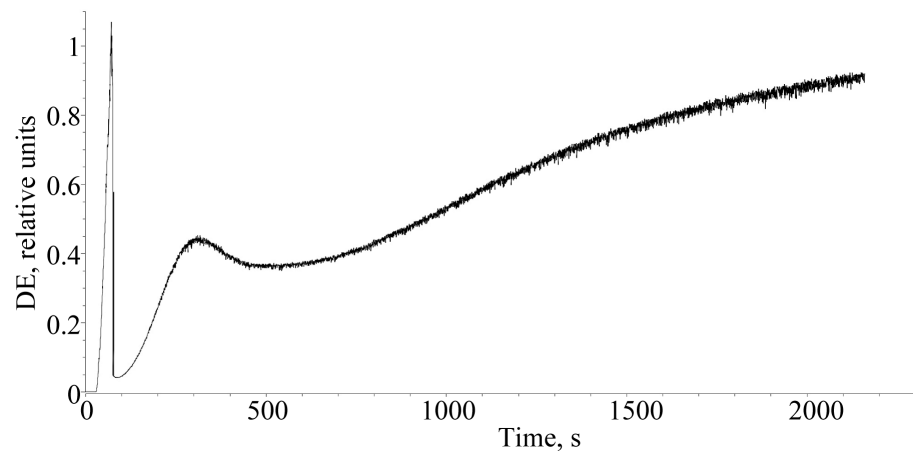

Figure 10. Coherent SE of $p$ - $p$ HG in sample W-75. Reflection mode, $532 \mathrm{~nm}$, HG period is $2 \mu \mathrm{m}$. DE $=1$ corresponds to the DE equal to the initial diffraction efficiency of HG recorded with two beams (the first peak). $\mathrm{SEF}=1.04$ was achieved after 72 minutes of exposure time (not shown). However, $\mathrm{SEF}=21$ if relative $\mathrm{DE}=0.05$ just after the first peak is assumed as the initial diffraction efficiency.

Coherent SE of scalar HG in transmission mode can be explained by the complementary HG recording in addition to the initial HG by minus first and zero order waves [3] [4] [10]. Using Kogelnik's coupled wave 


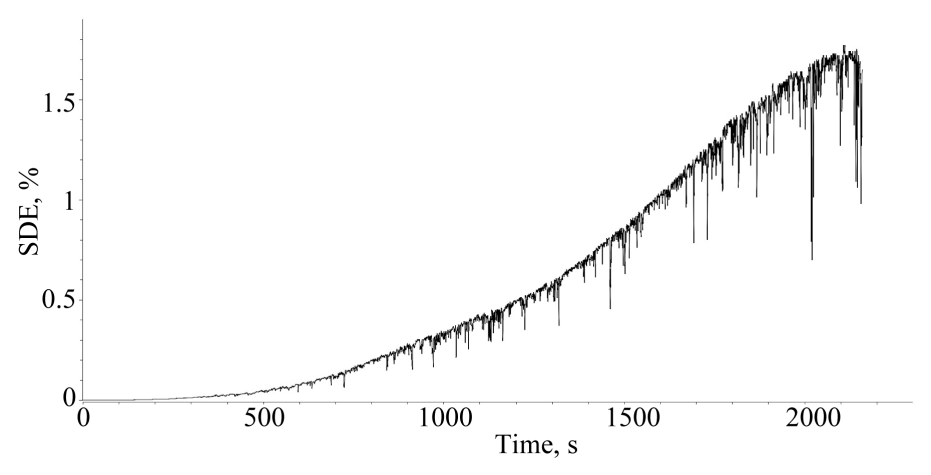

Figure 11. SDE exposure time dependence for sample 8a in the case of $p-p$ recording beam polarizations at $532 \mathrm{~nm}$ in transmission mode. HG period is $2 \mu \mathrm{m}$.

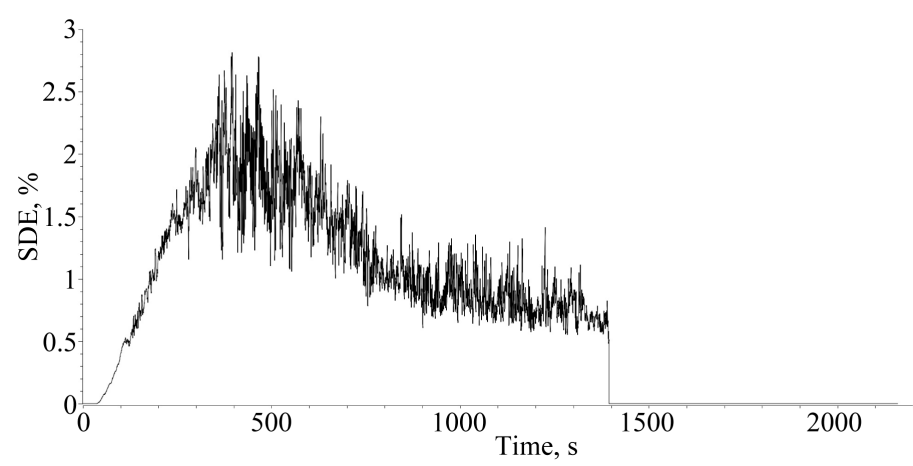

Figure 12. SDE exposure time dependence for sample 8a in the case of $p-p$ recording beam polarizations at $532 \mathrm{~nm}$ in reflection mode. HG period is $2 \mu \mathrm{m}$.

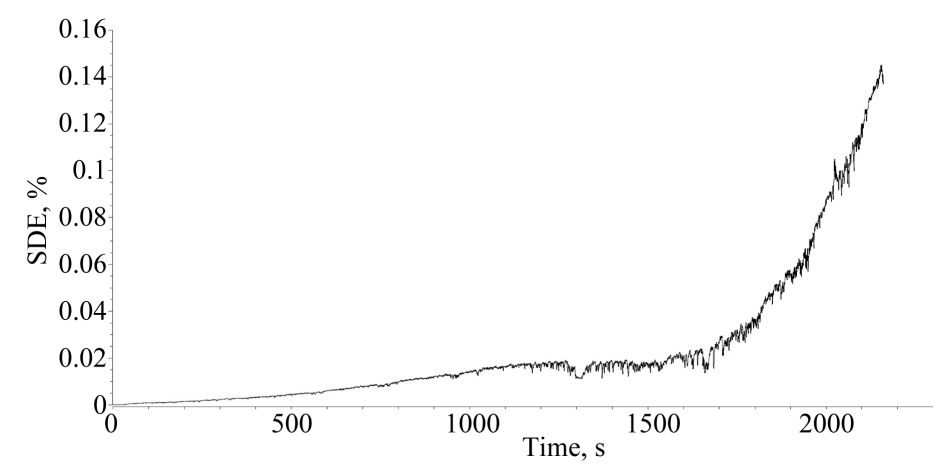

Figure 13. SDE exposure time dependence for sample 8a in the case of $s-p$ recording beam polarizations at $532 \mathrm{~nm}$ in transmission mode. HG period is $2 \mu \mathrm{m}$.

theory [14] the intensity distribution inside a thick HG can be found created by these waves:

$$
I_{i} \sim \exp \left(-\kappa_{0} z / \cos \theta_{i}\right)\left[\cosh \left(\kappa_{1} z / 2 \cos \theta_{i}\right)-\sinh \left(\kappa_{1} z / 2 \cos \theta_{i}\right) \cos K x+\sin \left(2 \pi n_{1} z / \lambda_{2} \cos \theta_{i}\right) \cos (K x-\pi / 2)\right]
$$

In Equation (1) the following new designations are used. $x$ and $z$ are the coordinates along the HG surface and depth, respectively. $\kappa_{0}, \kappa_{1}$ and $n_{1}$ are the average (over the thickness) absorption coefficient, the absoption modulation amplitude and the refractive index modulation amplitude of the initial cosinusoidal amplitude-phase HG. $\theta_{i}$ is the readout beam incidence angle inside the HG. $K=2 \pi / \Lambda$ is the HG angular frequency. Thus complementary volume amplitude HG (if $\kappa_{1}<0$, i.e., if bleaching takes place, as in our experiments) and com- 


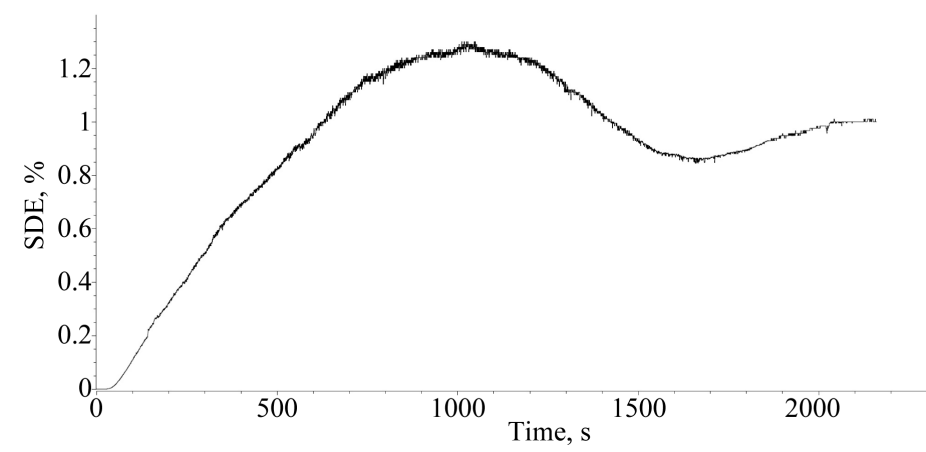

Figure 14. SDE exposure time dependence for sample 8a in the case of $\mathrm{s}-p$ recording beam polarizations at $532 \mathrm{~nm}$ in reflection mode. HG period is $2 \mu \mathrm{m}$.

Table 1. Maximal coherent SE factor values for studied samples in different modes. HG period is $2 \mu$ m. The maximum coherent SE factors are highlighted in each mode.

\begin{tabular}{|c|c|c|c|c|c|c|}
\hline Sample & $\begin{array}{l}\text { Transmission, } \\
532 \mathrm{~nm}, p-p\end{array}$ & $\begin{array}{l}\text { Transmission, } \\
532 \mathrm{~nm}, s-p\end{array}$ & $\begin{array}{l}\text { Reflection, } \\
532 \text { nm, } p-p\end{array}$ & $\begin{array}{l}\text { Reflection, } \\
532 \mathrm{~nm}, s-p\end{array}$ & $\begin{array}{l}\text { Transmission, } \\
633 \mathrm{~nm}, p-p\end{array}$ & $\begin{array}{c}\text { Transmission, } \\
633 \text { nm, } s-p\end{array}$ \\
\hline $8 a$ & 42 & $<1$ No SE & $<1$ Weak SE & $<1$ & 1.3 & $<1$ \\
\hline W-50 & 14 & 4.3 & $<1$ & $<1$ & - & - \\
\hline W-75 & 29 & $<1$ & 21 & $<1$ & $<1$ & 2 \\
\hline
\end{tabular}

Table 2. DE and SEF values in the course of the dark relaxation of HG recorded in sample $8 \mathbf{a}$ at 633 nm with $p$ - $p$ polarizations. Transmission mode. HG period is $2 \mu \mathrm{m}$.

\begin{tabular}{cccccc}
\hline Storage time, days & 8 & 21 & 33 & 41 & 218 \\
\hline $\mathrm{DE}, \%$ & 9.0 & 8.0 & 9.8 & 7.4 & 6.8 \\
$\mathrm{SEF} \xi=\mathrm{DE} / \mathrm{DE} E_{0}$ & 1 & 0.88 & 1.1 & 0.82 & 0.76 \\
\hline
\end{tabular}

plementary volume phase HG (shifted by $4 / 4$ ) enhancing the initial HG can be recorded if the recording mechanism is efficient enough.

However, in the case of thin HG the expression (1) is only approximately valid and incomplete. The complementary gratings by plus first and zero order waves are also recorded. The second complementary phase HG is shifted by $1 / 2$ with respect to the previous complementary HG thus possibly reducing the coherent SE effect. A careful mathematical treatment shows that this second complementary phase HG is inclined (by about $15^{\circ}$ in our experiments) with respect to the first one, and that its period is smaller (1.97 $\mu \mathrm{m}$ instead of $2.00 \mu \mathrm{m}$ in our experiments). Therefore, it is not precisely phase-shifted with respect to the first complementary HG by $\Lambda / 2$, and its reduction effect can be, most probably, neglected. This problem does not arise in the case of complementary amplitude HG because they both are shifted by $\Lambda / 2$ with respect to he initial HG thus both being in phase. We conclude that the model of complementary HG can be applied to explain the coherent SE effect of both thick and thin scalar transmission HG.

In addition to coherent SE of HG, incoherent light induced HG SE mechanisms are possible because of HG profile change, the HG contrast increase and the average absorption decrease in the case of photobleaching, and because of the peculiarities of photoinduced processes. Mathematical treatment of the first two mechanisms shows that their efficiency is not high (maximum SE factor less than 6) [5]. The third mechanism cannot be excluded but it needs further studies in molecular organic glasses. Our previous studies of incoherent light induced SE effect have shown that it is is much weaker than the coherent one [3].

The coherent SE of vector HG in the sample $\mathbf{W}-\mathbf{5 0}$ in transmission mode (maximal SE factor 4.3) shows that complementary HG recording is possible also with orthogonal diffracted waves (Figure 8).

Coherent SE of scalar HG in reflection mode is observed in samples 8a (weak SE after the initial decrease below the initial DE value) and W-75 (Figure 10). At the first glance, it seems that this effect is simply the consequence of coherent volume HG SE. However, there are three arguments against this proposal. First, 
coherent SE in reflection mode does not correlate with the coherent SE in transmission mode (e.g., Figure 9, Figure 10 and Table 1). Second, calculations show that if the diffraction in reflection mode is simply due to the reflection of beams diffracted inside the $\mathrm{HG}$ or due to the reflection coefficient modulation then relation $\mathrm{SDE}_{\mathrm{r}} \approx$ $0.02-0.04 \mathrm{SDE}_{\mathrm{t}}$ (subscripts $r$ and $t$ denote reflection and transmission modes) should take place. In our experiments at $532 \mathrm{~nm}$ the situation was quite opposite: $\mathrm{SDE}_{\mathrm{r}}>\mathrm{SDE}_{\mathrm{t}}$ (Figures 11-14). Third, as seen from Figures 11-14, SDE kinetic dependences are markedly different in transmission and reflection modes testifying that surface relief HG are recorded independently of volume HG.

Thus we conclude that coherent SE of HG in reflection mode is due to the SE of surface relief HG by the readout beam. The possible mechanism is the mass transport because of the force exerted between the optical electric field, $\boldsymbol{E}$, and the gradient in permittivity, $\varepsilon$ [1]. Its spatial density is

$$
\boldsymbol{f}=-0.5 \varepsilon_{0} E^{2} \nabla \varepsilon
$$

( $\varepsilon_{0}$ is the vacuum permittivity). Mass is thus driven out of areas with strong gradienti in $\varepsilon$ of initial HG, i.e., out of initial HG maxima. We have experimentally observed surface relief HG recording with $250 \mathrm{~nm}$ modulation in W-75 film by AFM measurements.

The absence of SE at $\Lambda=0.5 \mu \mathrm{m}$ and $\lambda_{1}=\lambda_{2}=633 \mathrm{~nm}$ (Figure 7), most probably, is due to the limited spatial resolution of sample 8a because the maximal DE at normal recording with two beams in this case is also only about $0.2 \%$ (SDE measurement was impossible due to the Bragg selectivity) compared to SDE $=45 \%$ at $\Lambda=2.0$ $\mu \mathrm{m}$ [12]. Thus HG relaxation processes prevail over the SE ones.

The absence of relaxational SE of HG in sample 8a, evidently, means that there are no mechanisms like periodically distributed mechanical stress induced HG enhancement as in a- $\mathrm{As}_{2} \mathrm{~S}_{3}$ films [2]. However, recently we have observed relaxational SE in other molecular glassy films [16].

In Table 3 we have compared the best coherent SE parameters of the best organic molecular glassy film $8 \mathbf{a}$ and of inorganic materials previously studied by us [2] [3] [5] [10]. One can conclude that until now inorganic materials are generally more efficient with respect to SE efficiency than organic ones the best being a- $\mathrm{As}_{2} \mathrm{~S}_{3}$ films with the maximal coherent SE factor of 1000 and SE efficiency of $3.0 \mathrm{~cm}^{2} / J$. However, SE effect in organic materials is less studied than in inorganic ones.

\section{Conclusions}

SE effect of scalar and vector holographic gratings (HG) recorded in azobenzene molecular glassy films 8a, $\mathbf{W}-\mathbf{5 0}$ and $\mathbf{W}-\mathbf{7 5}$ is experimentally studied in both transmission and reflection modes. Scalar HG have been recorded by two equally strong beams with parallel linear $p$-polarizations. Vector HG have been recorded with two equally strong beams with orthogonal linear $s$ - and $p$-polarizations. Experiments have been carried out mainly at $532 \mathrm{~nm}$ but some experiments were made also at $633 \mathrm{~nm}$.

The possibility of coherent SE effect of both scalar and vector holograms in organic materials is experimentally proved. Comparison with the known coherent SE results for inorganic materials has shown that until now inorganic materials exhibit generally higher SE efficiency.

It is found that coherent SE of thin HG can be quite efficient. The maximal SE factor (SEF) of 42 has been achieved in sample 8a at $532 \mathrm{~nm}$ in transmission mode. It is shown that the model of complementary HG can be applied also in thin HG case to explain coherent SE.

The possibility of vector HG coherent SE is experimentally demonstrated for the first time. SEF $=4.3$ is reached in sample $\mathbf{W}-\mathbf{5 0}$ in transmission mode at $532 \mathrm{~nm}$ and SEF $=2$ is reached in sample $\mathbf{W}-\mathbf{7 5}$ at $633 \mathrm{~nm}$.

The possibility of coherent HG SE in reflection mode also is established for the first time, as far as we know. $\mathrm{SEF}=21$ is found in sample $\mathbf{W}-\mathbf{7 5}$ at $532 \mathrm{~nm}$.

Table 3. Comparison of coherent SE parameters for different materials. AC stands for "additively coloured", $\mathrm{SEF}_{\max }$ is the maximal SE factor. Coherent SE was the most efficient in $\mathrm{a}-\mathrm{As}_{2} \mathrm{~S}_{3}$ films (highlighted).

\begin{tabular}{cccccc}
\hline Material & $\begin{array}{c}\mathrm{LiNbO}_{3} \\
\left(0.1 \mathrm{~mol}_{2} \mathrm{Fe}_{2} \mathrm{O}_{3}\right)\end{array}$ & $\mathrm{AC} \mathrm{KBr}$ & $\mathrm{a}-\mathrm{As}_{40} \mathrm{~S}_{15} \mathrm{Se}_{45}$ & $\mathrm{a}-\mathrm{As}_{2} \mathrm{~S}_{3}$ & $\mathbf{8 a}$ \\
\hline $\begin{array}{c}\mathrm{SEF}_{\max } \\
\begin{array}{c}\mathrm{SE} \text { efficiency, } \\
\alpha=(\xi-1) / \mathrm{It}, \mathrm{cm}^{2} / \mathrm{J}\end{array}\end{array}$ & 50 & 4.5 & 1.55 & 1000 & 42 \\
\hline
\end{tabular}


It is experimentally demonstrated that HG recording processes as well as coherent SE processes in studied molecular glassy films in transmission and reflection modes are practically independent. In transmission mode mainly the volume HG is monitored and coherent SE of volume HG takes place whereas in reflection mode the surface relief HG is monitored and coherent SE of surface relief HG takes place. In the latter case the permittivity gradient mechanism is proposed.

Both HG recording efficiency and coherent SE efficiency dramatically decrease in sample 8a in transmission mode at $633 \mathrm{~nm}$ when the HG period is decreased from $2 \mu \mathrm{m}$ to $0.5 \mu \mathrm{m}$. This is explained by the limited spatial resolution of material.

No relaxational SE effect is found in sample $\mathbf{8 a}$ at $633 \mathrm{~nm}$.

\section{Acknowledgements}

This work has been supported by the European Regional Development Fund within the project No 2010/0270/ 2DP/2.1.1.1.0/10/APIA/VIAA/002 .

\section{References}

[1] Zhao, Y. and Ikeda, T. (2009) Smart Light-Responsive Materials.Azobenzene-Containing Polymers and Liquid Crystals. John Wiley \& Sons, Inc., Hoboken. http://dx.doi.org/10.1002/9780470439098

[2] Ozols, A., Salminen, O. and Reinfelde, M. (1994) Relaxational Self-Enhancement of Holographic Gratings in Amorphous $\mathrm{As}_{2} \mathrm{~S}_{3}$ Films. Journal of Applied Physics, 75, 3326-3334. http://dx.doi.org/10.1063/1.356141

[3] Ozols, A., Nordman, N., Salminen, O. and Riihola, P. (1997) Holographic Recording in Amorphous Semiconductor Films. Proceedings of SPIE, 2968, 282-291. http://dx.doi.org/10.1117/12.266849, http://dx.doi.org/10.1117/12.266854

[4] Gaylord, T.K., Rabson, T.A., Tittel, F.K. and Quick, C.R. (1973) Self-Enhancement of $\mathrm{LiNbO}_{3}$ Holograms. Journal of Applied Physics, 44, 896-897. http://dx.doi.org/10.1063/1.1662282

[5] Ozols, A.O. (1979) Self-Enhancement of Amplitude Holograms in Additively Coloured KBr Crystals. Latvijas PSR Zinātñu Akadēmijas Vēstis Fiz. Tehn.Zin.Sērija, 45-52 (in Russian).

[6] Rickermann, F., Riehemann, S., Buse, K., Dirksen, D. and von Bally, G. (1996) Diffraction Efficiency Enhancement of Holographic Gratings in $\mathrm{Bi}_{12} \mathrm{Ti}_{0.76} \mathrm{~V}_{0.24} \mathrm{O}_{20}$ Crystals after Recording. Journal of the Optical Society of America B, 13, 2299-2305. http://dx.doi.org/10.1364/JOSAB.13.002299

[7] Pashkevich, V., Ketolainen, P. and Salminen, O. (1996) Holographic Self-Amplification in Amorphous As-Se Semiconductor Films. Journal of Modern Optics, 43, 1563-1567.

[8] Grzymala, R. and Keinonen, T. (1998) Self-Enhancement of Holographic Gratings in Dichromated Gelatin and Polyvinyl Alcohol Films. Applied Optics, 37, 6623-6626. http://dx.doi.org/10.1364/AO.37.006623

[9] Aleksejeva, J. andTeteris, J. (2010) Volume Grating Recording in Acrylate-Based Photopolymers. Latvian Journal of Physics and Technical Sciences, 13-22.

[10] Shvarts, K., Ozols, A., Augustov, P. and Reinfelde, M. (1987) Photorefraction and Self-Enhancement of Holograms in $\mathrm{LiNbO}_{3}$ and $\mathrm{LiTaO}_{3}$ Crystals. Ferroelectrics, 75, 231-249.

[11] Ozols, A., Kampars, V., Reinfelde, M. and Kokars, V. (2003) Hologram Recording in Azobenzene Oligomers. Proceedings of SPIE, 5123, 102-109.

[12] Ozols, A., Kokars, V., Augustovs, P., Uiska, I., Traskovskis, K., Mezinskis, G., Pludons, A. and Saharov, D. (2010) Polarization Dependence of Holographic Recording in Glassy Azocompounds. Lithuanian Journal of Physics, 50, 17-25.

[13] Ozols, A., Saharov, D., Kokars, V., Kampars, V., Maleckis, A., Mezinskis, G. and Pludons, A. (2010) Holographic Recording of Surface Relief Gratings in Stilbene Azobenzene Deriavatives at $633 \mathrm{~nm}$. Journal of Physics: Conference Series, 249, 1-8, http://dx.doi.org/10.1088/1742-6596/249/1/012055

[14] Kogelnik, H. (1969) Coupled Wave Theory for Thick Hologram Gratings. Bell System Technical Journal, 48, 29092947. http://dx.doi.org/10.1002/j.1538-7305.1969.tb01198.X

[15] Fang, G.J., Maclennan, J.E., Yi, Y., Glaser, M.A., Farrow, M., Korblova, E., Walba, D.M., Furtak, T.E. and Clark, N.A. (2013) Athermal Photofluidization of Glasses. Nature Communications, 4, 1-10. http://dx.doi.org/10.1038/ncomms2483

[16] Ozols, A., Augustovs, P., Kokars, V., Traskovskis, K. and Saharov, D. (2013) Effect of Holographic Grating Period on Its Relaxation in a Molecular Glassy Film. IOP Conference Series: Materials Science and Engineering, 49, 1-6. http://dx.doi.org/10.1088/1757-899X/49/1/012043 
Scientific Research Publishing (SCIRP) is one of the largest Open Access journal publishers. It is currently publishing more than 200 open access, online, peer-reviewed journals covering a wide range of academic disciplines. SCIRP serves the worldwide academic communities and contributes to the progress and application of science with its publication.

Other selected journals from SCIRP are listed as below. Submit your manuscript to us via either submit@scirp.org or Online Submission Portal.
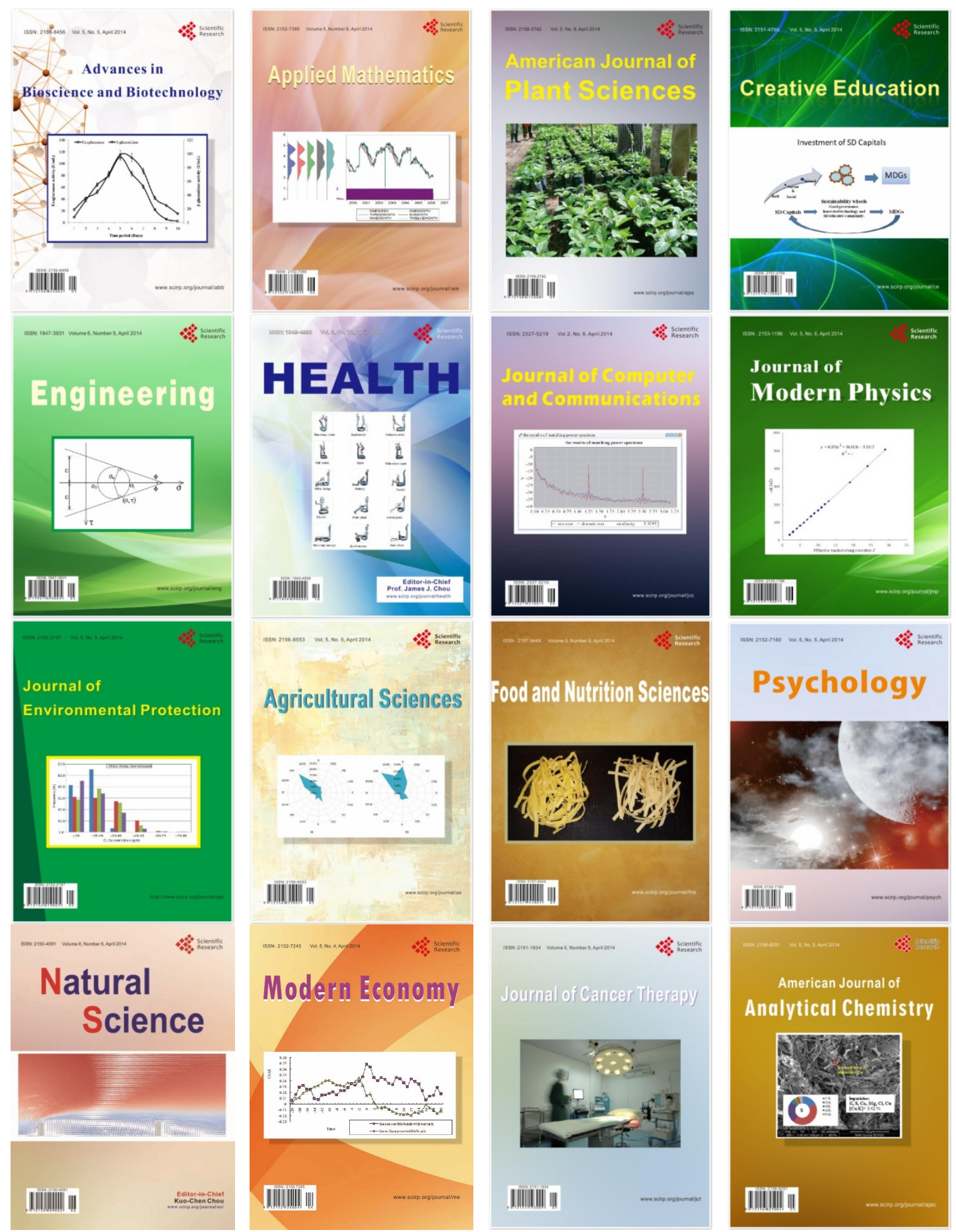